\title{
Effect of Nd: YAG laser capsulotomy on IOP rise and its variation with energy used
}

\author{
Prempal Kaur', Priyanka Gusain, ${ }^{2, *}$, Chandu Mohan ${ }^{3}$, Jaspreet Bedi $^{4}$ \\ ${ }^{1}$ Professor and HOD, ${ }^{2}$ Junior Resident, ${ }^{3,4}$ Senior Resident, Dept. of Ophthalmology, Government Medical College, Amritsar, \\ Punjab, India
}

*Corresponding Author:

Email: priyanka.open.with.smile@gmail.com

\begin{abstract}
Aim: To study the effect of YAG laser capsulotomy on visual acuity with special reference to IOP changes and its correlation to the energy used in pseudophakics.

Materials and Methods: A total of 120 cases of pseudophakic eyes having intraocular pressure (IOP) between $10-20 \mathrm{mmHg}$ were included. After detailed history and ocular examination including visual acuity, slit lamp biomicroscopy, fundus and applanation tonometry, laser capsulotomy was performed to clear off $4-5 \mathrm{~mm}$ visual axis. High $(>50 \mathrm{~mJ})$ and low $(<50 \mathrm{~mJ})$ energy groups were divided according to the energy used during procedure. Post- laser IOP was noted immediately, at 1 hour, 2 hour, 4 hours, 24 hours, seventh day and on 1 month by Goldmann applanation tonometer.

Results: $95 \%$ of the cases showed improved visual acuity, after laser capsulotomy. Elevated IOP was seen in 75 cases, out of which $80 \%$ of them showed transient IOP rise within 2 hour whereas no elevation was seen in 45 cases. IOP change was significantly high in high energy group $(\mathrm{p}=0.000)$ than in low energy.

Conclusion: Post- laser IOP rise is minimal and transient. It varies with the amount of energy used. Routine pre and post antiglaucoma medication can be avoided and minimal laser energy should be used.
\end{abstract}

Keyword: Intraocular pressure, Nd: YAG laser, Posterior capsule opacification, Visual acuity.

\section{Introduction}

Posterior capsule opacification (PCO) is the most common late complication of uncomplicated cataract surgery which is caused by the proliferation of lens epithelial cells (LECs) that have remained within capsular bag following cataract extraction.

Globally, incidence of posterior capsular opacification (PCO) varies in different studies from 7 to $31 \%$ for 2 years after the surgery. ${ }^{1}$

Elsching's pearls, wrinkling and fibrosis are the various types of PCO. The central part of posterior capsule is opened either surgically or with laser which is considered as the standard treatment. Nd: YAG laser posterior capsulotomy is a convenient and non-invasive procedure that has restricted the need for surgical intervention. ${ }^{2}$ Raised intraocular pressure (IOP) is one of the frequent complication but transient in nature. ${ }^{3}$ Other complications of this procedure are cystoids macular edema, retinal detachment, IOL pitting and corneal burns. ${ }^{4,5}$

The current study was an endevoure to find out the efficacy of YAG laser capsulotomy on visual acuity, intraocular pressure and its variation with energy used in pseudophakic eyes.

\section{Materials and Methods}

This was a prospective interventional study of 120 cases with significant posterior capsular opacification (PCO) following small incision cataract surgery (SICS) with posterior chamber intraocular lens (PCIOL) implantation after obtaining written informed consent. The study period was from August 2016 to January 2017 at Regional Institute of Ophthalmology, GMC, Amritsar.

\section{Inclusion Criteria:}

1. Significant PCO imparing visual acuity.

2. Minimum period of 4 months following uncomplicated cataract surgery.

3. Patient age group $>20$ years.

4. Pre-laser IOP/ baseline IOP between $10-20 \mathrm{mmHg}$.

5. Quiet eye with no inflammation.

Exclusion Criteria:

1. Patients on antiglaucoma medications.

2. Eyes with inflammation, corneal diseases, diabetic retinopathy, posterior segment disease or any systemic disease.

Detailed history and complete ocular examination including slit-lamp examination to assess PCO, best corrected visual acuity (BCVA), fundus examination, IOP measurement by Goldmann applanation tonometer (GAT) were done before Nd: YAG laser capsulotomy procedure.

Patient underwent Nd: YAG laser capsulotomy procedure to clear off central $4 \mathrm{~mm}$ visual axis by using Abraham capsulotomy contact lens. Energy used in this procedure was divided as 'low energy', if it was $<50 \mathrm{~mJ}$ and 'high energy' if it was $>50 \mathrm{~mJ}$.

Goldmann applanation tonometer was used to record post-laser IOP immediately, then after 1 hour, 2 hours, 4 hours, 24 hours, $7^{\text {th }}$ day and 1 month from the date of laser application. After the procedure, topical diclofenac eye drop was prescribed thrice a day for 1 week. If there was significant rise in IOP after laser capsulotomy, then antiglaucoma medication was also given. The data thus collected, were tabulated \& Statistical products and services solution (SPSS version 17.0) was used for the statistical analysis. Unpaired ttest was used for comparison of quantitative variables 
(pre-laser IOP, post-laser IOP, energy used, IOP change) between low and high energy group. Correlation between IOP change and energy used was determined by correlation co-efficient and presented in scatter diagram. P-value $\leq 0.05$ was considered statistically significant.

\section{Results}

In the present study age of patients were between $30-80$ years (mean age of $61.8 \pm 7.69$ years). $62 \%$ were males and $38 \%$ were females.

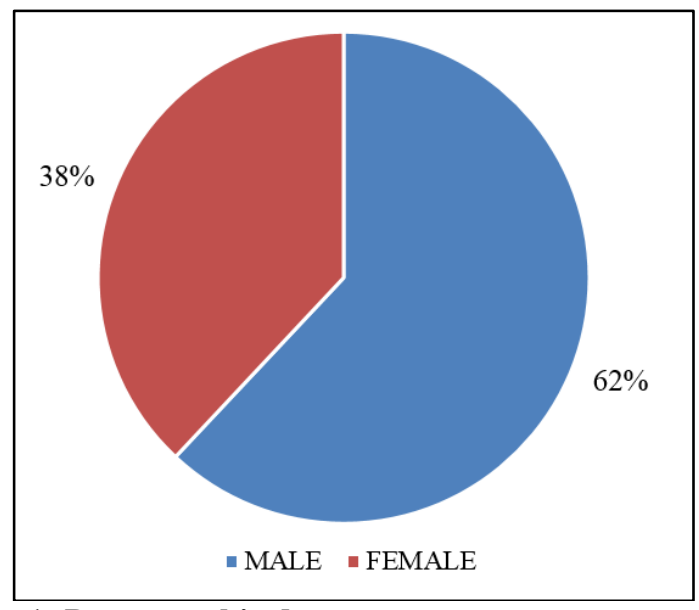

Fig. 1: Demographic data

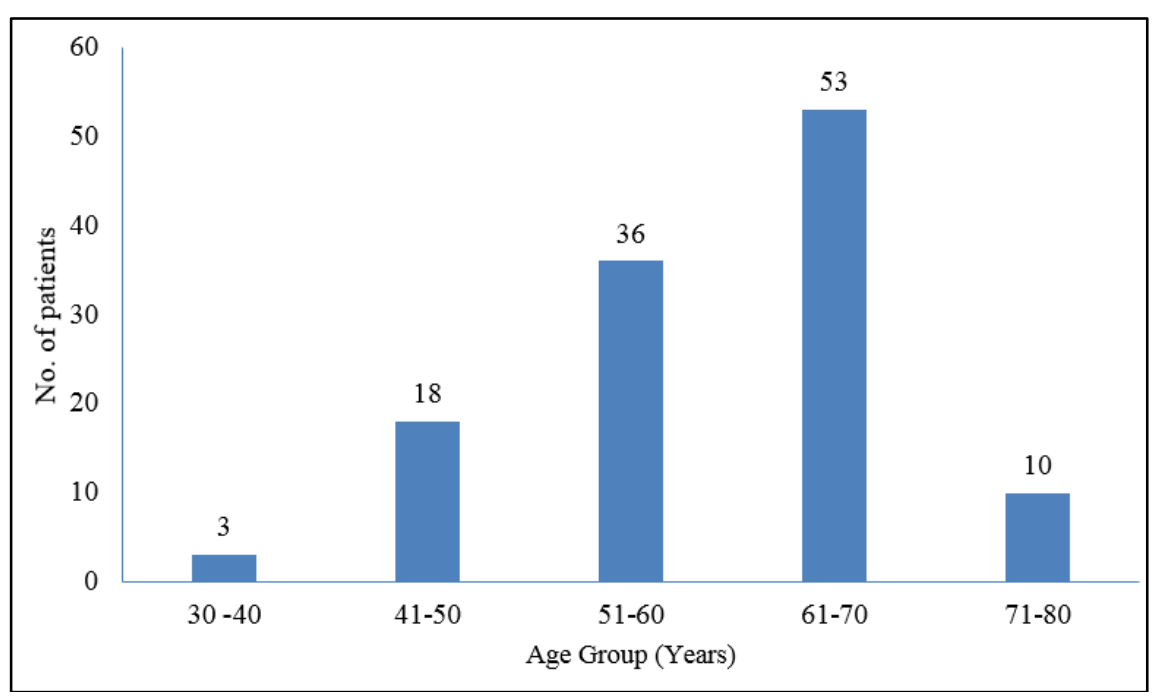

Fig. 2: Age group

Table 1: Distribution of patients according to pre- laser and post - laser capsulotomy visual acuity

\begin{tabular}{|l|c|c|c|c|c|}
\hline S. No & Visual acuity & \multicolumn{2}{c|}{$\begin{array}{c}\text { Patients (Pre-laser) } \\
\text { No. }(\mathbf{n = 1 2 0})(\boldsymbol{\%})\end{array}$} & \multicolumn{2}{c|}{$\begin{array}{c}\text { Patients (Post-laser) } \\
\text { No. }(\mathbf{n = 1 2 0})(\boldsymbol{\%})\end{array}$} \\
\hline 1. & $6 / 9-6 / 6$ & 0 & 0 & 31 & 25.82 \\
\hline 2. & $6 / 12$ & 14 & 11.66 & 25 & 20.83 \\
\hline 3. & $6 / 18$ & 25 & 20.83 & 30 & 24.99 \\
\hline 4. & $6 / 24$ & 40 & 33.32 & 20 & 16.66 \\
\hline 5. & $6 / 36$ & 20 & 16.66 & 8 & 6.66 \\
\hline 6. & $6 / 60$ & 15 & 12.5 & 3 & 2.49 \\
\hline 7. & $<6 / 60$ & 6 & 4.99 & 3 & 2.49 \\
\hline
\end{tabular}

Table 2: Distribution of patients showing improvement in visual acuity after laser capsulotomy

\begin{tabular}{|l|c|c|c|}
\hline S. No & VA (Improvement) & $\begin{array}{c}\text { No. of patients } \\
(\mathbf{n = 1 2 0})\end{array}$ & Percentage (\%) \\
\hline 1. & 1 line & 51 & 42.49 \\
\hline 2. & 2 line & 42 & 34.99 \\
\hline 3. & 3 line & 13 & 10.83 \\
\hline 4. & 4 line & 6 & 4.99 \\
\hline 5. & 5 line & 2 & 1.66 \\
\hline 6. & 6 line & 1 & 0.83 \\
\hline 7. & No improvement & 5 & 4.16 \\
\hline
\end{tabular}


$4.99 \%$ patients had $\mathrm{VA} \leq 6 / 60$ before the laser capsulotomy procedure and none of patient had VA of $6 / 9$ or more. $25.83 \%$ had VA of $\geq 6 / 9$ and only $2.49 \%$ patients had VA of $\leq 6 / 60$ after laser capsulotomy.

Table 3: No. of patients with IOP changes after laser capsulotomy

\begin{tabular}{|l|c|c|c|}
\hline S. No & $\begin{array}{c}\text { IOP changes } \\
(\mathbf{m m H g})\end{array}$ & $\begin{array}{c}\text { No. of } \\
\text { patients } \\
(\mathbf{n = 1 2 0})\end{array}$ & $\mathbf{( \% )}$ \\
\hline 1. & No rise & 45 & 37.48 \\
\hline 2. & $1-5$ & 64 & 53.31 \\
\hline 3. & $6-10$ & 6 & 4.99 \\
\hline 4. & $11-15$ & 3 & 2.49 \\
\hline 5. & $>15$ & 2 & 1.66 \\
\hline
\end{tabular}

75 patients $(63 \%)$ showed rise in IOP whereas no elevation was seen in 45 patients (37\%). Maximum $(53.3 \%)$ showed IOP elevation $\leq 5 \mathrm{mmHg}$ and only 9.14 $\%$ showed elevation in IOP $>5 \mathrm{mmHg}$.

Table 4: Mean IOP elevation with respect to time interval after laser capsulotomy

\begin{tabular}{|l|c|c|c|}
\hline S. No & Time interval & $\begin{array}{c}\text { Mean } \\
\text { IOP }\end{array}$ & S.D. \\
\hline 1. & $\begin{array}{c}\text { Pre-laser/base } \\
\text { line IOP }\end{array}$ & 14.45 & 2.52 \\
\hline 2. & $1 \mathrm{hr}$ & 16.08 & 3.69 \\
\hline 3. & $2 \mathrm{hr}$ & 16.83 & 3.69 \\
\hline 4. & $4 \mathrm{hr}$ & 16.04 & 2.94 \\
\hline 5. & $24 \mathrm{hr}$ & 15.11 & 2.55 \\
\hline 6. & $7^{\text {th }}$ day & 14.58 & 2.52 \\
\hline 7. & $28^{\text {th }}$ day & 14.22 & 2.55 \\
\hline
\end{tabular}

Baseline mean IOP was $14.45 \pm 2.52 \mathrm{mmHg}$ and after laser capsulotomy procedure peak mean IOP at 2 hours was $16.83 \pm 3.69 \mathrm{mmHg}$.
Table 5: No. of patients with elevation in IOP according to time interval after laser capsulotomy

\begin{tabular}{|l|c|c|c|}
\hline S. No & Time interval & $\begin{array}{c}\text { No. of } \\
\text { patients } \\
(\mathbf{n = 7 5 )}\end{array}$ & $\mathbf{\%}$ \\
\hline 1. & $0-2 \mathrm{hr}$ & 60 & 80 \\
\hline 2. & $2-4 \mathrm{hr}$ & 13 & 16 \\
\hline 3. & After $24 \mathrm{hr}$ & 2 & 2.66 \\
\hline 4. & 1 week & 0 & 0 \\
\hline 5. & 1 month & 0 & 0 \\
\hline
\end{tabular}

Out of 75 patients with elevation in IOP, $80 \%$ of them showed transient rise in IOP within 2 hour after laser capsulotomy procedure.

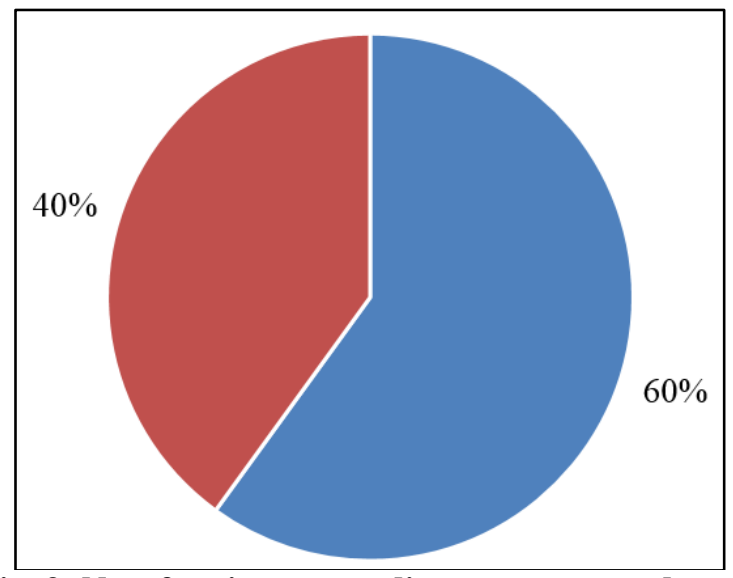

Fig. 3: No. of patients according to energy used

$60 \%$ of patients belonged to high energy group while $40 \%$ of patients belonged to low energy group.

Table 6: Pre-laser and Post-laser IOP, energy used, rise in IOP values versus category of energy used (group statistics

\begin{tabular}{|l|c|c|c|}
\hline \multirow{2}{*}{\multicolumn{1}{|c|}{ Outcome }} & \multicolumn{2}{|c|}{ Category of energy used } & \multirow{2}{*}{$\begin{array}{c}\text { Significance } \\
\text { p-value }\end{array}$} \\
\cline { 2 - 3 } & High $>50(\mathrm{n}=49)$ & Low $<50(\mathrm{n}=71)$ & 0.531 \\
\hline Pre -laser IOP & $14.27 \pm 2.75$ & $14.57 \pm 2.37$ & 0.008 \\
\hline Post-laser (IOP peak) & $19.23 \pm 4.27$ & $15.73 \pm 2.88$ & 0.000 \\
\hline Energy used & $62.46 \pm 10.07$ & $38.01 \pm 9.34$ & 0.000 \\
\hline IOP values & $4.96 \pm 3.94$ & $1.15 \pm 1.54$ & \\
\hline
\end{tabular}

IOP change (difference between post-laser IOP peak and pre-laser IOP) in low energy category was $1.15 \pm 1.54 \mathrm{mmHg}$ while in high energy category, it was
$4.96 \pm 3.94 \mathrm{mmHg}$ which was statistically significant $(\mathrm{p}=0.000)$. 


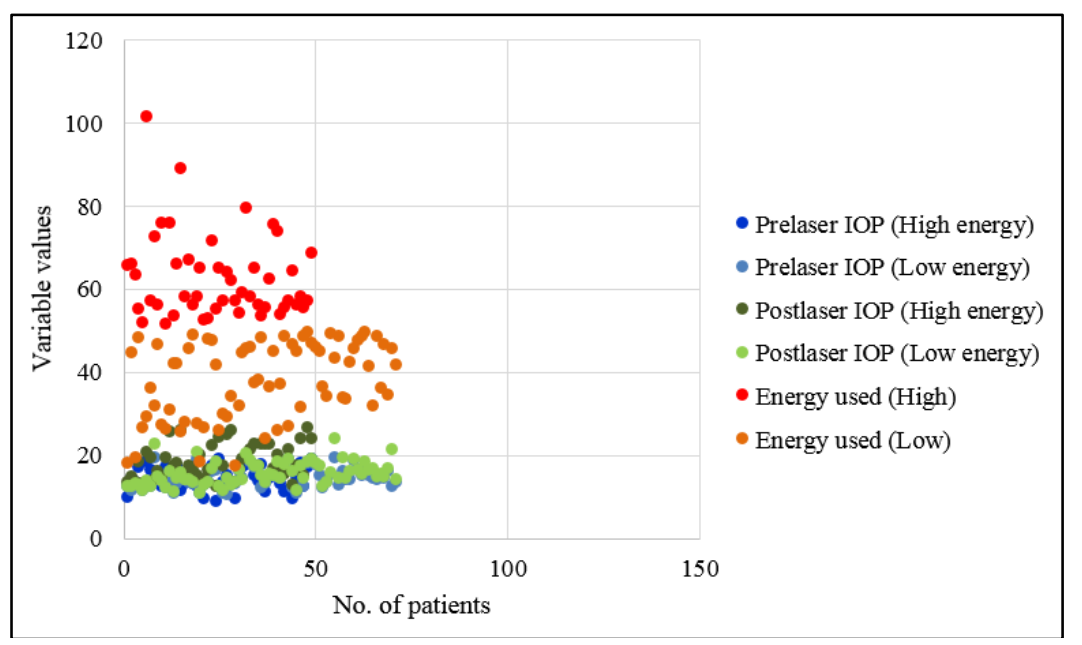

Fig. 4): Scatter diagram depicting significantly positive/direct correlation between IOP change and energy used $(r=0.518 ; p=0.000)$

\section{Discussion}

PCO causes glare, impairs contrast sensitivity and remains a major concern of decreased vision after cataract surgery. Nd: YAG laser is the most effective procedure for the treatment of PCO. It breaks the capsule following the pressure wave created by infrared light of $1064 \mathrm{~nm}$ which is amplified and focused so that electrons are ripped away from nuclei to form energy plasma and corresponding shock wave. ${ }^{6}$

In our study, out of 120 patients, $62 \%$ were males and $38 \%$ females. Majority of them (74.12\%) were in 51-70 year age group. It was the also commonest age group who underwent cataract surgery.

A similar trend was reported in the study conducted by Shetty NK and Sridhar $\mathrm{N}$ et $\mathrm{al}^{7}$ found, there were 21 males $(60 \%)$ and 14 females (40\%); amongst whom $68.6 \%$ were in 50-70 years age group.

In our study, $95 \%$ of patients showed improvement in visual acuity after laser capsulotomy. Similar findings were seen by Mahtab Alam et al, ${ }^{8}$ Abid Naseemet al, ${ }^{9}$ Mohd. Younis et al ${ }^{10}$ who also reported that $90 \%$ of cases after laser capsulotomy procedure showed significant improvement in visual acuity.

The current study showed none of patients with decreased vision whereas no improvement in visual acuity was seen in about $2.49 \%$ patients which could be explained because of pre-existing abnormal fundus which got undetected due to thick fibrous posterior capsule.

Out of 120 patients, $75(62.47 \%)$ of them showed transient rise in IOP in our study. Gore VS ${ }^{11}$ and Maqsood A. Burq et al $^{12}$ also concluded transient IOP rise in $59.4 \%$ and $56.2 \%$ of cases respectively which is comparable to our study. Flohr et $\mathrm{al}^{13}$ and Mohammed YK et $\mathrm{al}^{10}$ found IOP elevation in $>75 \%$ and $84 \%$ of cases respectively in their studies.

In a study by Singh $\mathrm{M}$ and Sharma $\mathrm{N}$ et al,,${ }^{14}$ the rise in IOP from baseline at 1 hour, 3 hour, 5 hour and 24 hours post-procedure was not found to be significant in the groups receiving ocular hypotensive drug whereas in the group receiving placebo, the rise of IOP reached statistical significance at 1,3 and 5 hours post -laser which came down to insignificant levels in 24 hours.

Hassan KS et al ${ }^{15}$ and $\mathrm{Kraff} \mathrm{CM}$ et $\mathrm{al}^{16}$ who reported average IOP rise by $6 \mathrm{mmHg}$ and $3.5 \mathrm{mmHg}$ after laser capsulotomy respectively were also in concordance to our study results.

Different studies explain various factors for IOP rise after laser capsulotomy which were presence of IOL in the bag or sulcus fixation, baseline IOP, glaucomatous patients, different types of PCO, different timing of IOP recording, capsulotomy size, initial preprocedure treatment prescribed etc.

In the present study pre-laser mean IOP was 14.45 $+2.52 \mathrm{mmHg}$ which raised to $16.08+3.69 \mathrm{mmHg}$ at 1 hour and peaked to $16.83 \pm 3.69 \mathrm{mmHg}$ by 2 hour after laser capsulotomy procedure and then declined towards pre-laser IOP value. Our study corresponds with the studies conducted by Ge $\mathrm{J}$ et al ${ }^{17}$ and Dawood $\mathrm{Z}$ et al ${ }^{18}$ where they concluded transient IOP rise within 1.5- 4 hour and 1-3 hour after laser capsulotomy procedure respectively and then declined towards pre-laser IOP value in their study. The results of the current study showed IOP change more common in high energy category $(4.96 \pm 3.94 \mathrm{mmHg})$ than low energy category $(1.15 \pm 1.54 \mathrm{mmHg})$ which agree with Channel and Beckman et al ${ }^{19}$ study. The more the energy used during the procedure, the more particles liberated from posterior capsule breakdown and acute inflammatory cells which resulted in clogging of anterior chamber angle, impaired aqueous flow and lead to raised IOP.

\section{Conclusion}

Post laser IOP rise is minimal and transient. It varies with the amount of energy used. Routine pre and post antiglaucoma medication can be avoided and minimum possible energy should be given. 


\section{References}

1. Waseem M, Khan HA. Association of raised intraocular pressure and its correlation to the energy used with raised versus normal intraocular pressure following Nd: YAG laser posterior capsulotomy in pseudophakics. J CPSP. 2010;20(8):524-27.

2. Murril CA, Stanfield DL, Van Brockiln MD.

Capsulotomy. Optom Clin. 1995;4: 69-83.

3. Burq MA, Taqui AM. Frequency of retinal detachment and other complications after neodymium: YAG laser capsulotomy. JPMA. 2008;58(10):550-552.

4. Alimanovic-Halilovic E. Correlation between eye aperture diameter and complications in the posterior eye segment after Nd: YAG Laser capsulotomy. Bosn J Basic Med Sci. 2008;8(2):106-109.

5. Awasthi N, Guo S, Wagner BJ. Posterior Capsular Opacification. Arch Ophthalmol. 2009;127(4):555-562.

6. Bath PE, Fankhauser F. Long-term results of Nd: YAG laser posterior capsulotomy with the Swiss laser. $J$ Cataract Refract Surg. 1986;12(2):150-153.

7. Shetty NK, Sridhar S. Study of variation in intraocular pressure (IOP) following Nd:YAG laser capsulotomy. $J$ Clin Diagn Res. 2016;10(12):09-12.

8. Mahtab AK, Shafi MJ, Narsani AK, Syed AD, Gul S. Is the Nd: YAG laser a safe procedure for posterior capsulotomy? Pak J Ophthalmol. 2008;24(2):121-123.

9. Abid N, Faizur R. Haroon R Tariq. Visual outcome and complications after Nd: YAG laser capsulotomy in patients with posterior capsular opacification. Pak J Med Res. 2010;49(2):22-24.

10. Mohammad YK, Jan S, Mohammad NK, Khan S, Kundi $\mathrm{N}$. Visual outcome after Nd: YAG capsulotomy in posterior capsular opacification. Pak J Ophthalmol. 2006;22(2):87-91.

11. Gore VS. The study of complications of Nd: YAG laser capsulotomy. International Journal of Bioinformative Research. 2012;4(2):256-268.
12. Maqsood AB, Ather MT. Frequency of retinal detachment and other complication after Neodymium: YAG laser capsulotomy. J Pak Med Assoc. 2008;58(10):550-552.

13. Flohr MJ, Robin AL, Kelley JS. Early complications following Q-switched Neodymium: YAG laser posterior capsulotomy. Ophthalomology. 1985;92(3):360-363.

14. Singh M, Sharma N. Anterior segment Nd: YAG laser procedures: To study intraocular pressure spikes and their prevention. Delhi Journal of Ophthalmology. 2015;26(2):93-96.

15. Hasan KS, Adhi MI, Aziz M et al. Nd: YAG laser posterior capsulotomy. Pak J Ophthalmol. 1996;12:3-7.

16. Kraff MC et al. Intraocular pressure and the corneal endothelium after Nd: YAG laser posterior capsulotomy, Relative effects of aphakia and pseudophakia. Arch Ophthalmol. 1985;103(4):511-514.

17. Ge J, Wand M, Chiang R et al. Long term effect of $\mathrm{Nd}$ : YAG laser posterior capsulotomy on intraocular pressure. Arch Ophthalmol. 2000;118(10):1334-1337.

18. Dawood Z, Mirza SA, Qadeer A. Review of 560 cases of YAG laser capsulotomy. J Liaquat Univ Med Health Sci. 2007;6(1):3-7.

19. Channell MM, Beckman H. Intraocular pressure changes after Nd: YAG laser posterior capsulotomy. Arch Ophthalmol. 1984;102(7):1024-1026.

How to cite this article: Kaur $\mathrm{P}$, Gusain $\mathrm{P}$, Mohan C, Bedi J. Effect of Nd: YAG laser capsulotomy on IOP rise and its variation with energy used. Ind J Clin Exp Ophthalmol. 2018;4(3):396-400. 